\title{
The Effect of Plasmid-determined and Other Characteristics on the Survival of Escherichia coli in the Alimentary Tract of Two Human Beings
}

\author{
By H. WILLIAMS SMITH AND M. B. HUGGINS \\ Houghton Poultry Research Station, Houghton, Huntingdon, Cambridgeshire PE17 2DA
}

(Received 15 May 1978; revised 24 July 1978)

\section{INTRODUCTION}

Little is known about the influence that different characteristics of bacteria have on their ability to survive in the alimentary tract of healthy human beings. A recent investigation (Smith \& Huggins, 1976) in which two human beings consumed mixtures of pairs of cultures of an Escherichia coli strain showed that the ColV plasmid promoted survival in the alimentary tract but the ColE plasmid had no observable effect. These studies have now been extended to obtain information on the influence of other bacterial characteristics, both plasmid and chromosomally determined, on survival; the results are reported in this paper.

In an investigation of this nature, the choice of the parent $E$. coli strain is particularly important. Because only poor selection methods exist for detecting many plasmid-determined characteristics, it must be a good plasmid recipient. It should also be capable of surviving in the alimentary tract long enough for adequate observations to be made on each characteristic but not excessively long, otherwise the number of characteristics that can be studied becomes limited. The $E$. coli strain chosen was a good recipient and usually persisted in the alimentary tract of the two human beings used in the investigation for about 6 to $10 \mathrm{~d}$ after oral inoculation.

\section{METHODS}

Infecting strain of $E$. coli. This was $\mathrm{H} 209$, an $09: \mathrm{K} 31: \mathrm{H} 4$ strain that had been isolated from the faeces of a healthy human being; it was used as a spontaneous chromosomal mutant resistant to sodium nalidixate.

Preparation of plasmid-carrying derivatives of strain $\mathrm{H} 209$. These were prepared by the methods of Smith \& Huggins (1976) for ColV and ColVI-K94 (Fredericq, 1963), Smith \& Linggood (1971 b) for Ent, K88 and Hly, Smith (1974) for Vir, Smith \& Parsell (1975) for Suc and Raf, Ørskov \& Ørskov (1973) for $\mathrm{H}_{2} \mathrm{~S}$, and Smith (1970) for R1, R100, de-repressed F, repressed F and derepressed I. F and I were linked to a tetracycline resistance determinant to aid the selection of $\mathrm{H} 209$ organisms that had acquired them. The Ent ${ }^{+} \mathrm{H}^{209}$ strain synthesized heat-labile (LT) and heat-stable (ST) enterotoxin; its plasmid had been obtained from a strain of E. coli enteropathogenic for pigs. The Hly ${ }^{+} \mathrm{Tra}^{-}$strain had been obtained by transferring a nonconjugative Hly plasmid from an $E$. coli $\mathrm{K} 12$ strain to $\mathrm{H} 209$ with $\mathrm{F}$ and then eliminating $\mathrm{F}$ by sodium laury] sulphate treatment (Tomoeda et al., 1968).

Preparation of chromosomal mutants of strain $\mathrm{H} 209$. The mutant that did not produce the $\mathrm{K} 31$ antigen $\left(\mathrm{K}^{3} 1^{-}\right)$was obtained by visual examination of six plates of MacConkey agar that had been inoculated with the stock $\mathrm{H} 209$ culture in a manner that yielded numerous discrete colonies after incubation at $37^{\circ} \mathrm{C}$ for $24 \mathrm{~h}$. One colony darker than the rest was shown by Dr B. Rowe of the Central Public Health Laboratory to have the antigenic structure $09: \mathrm{K} 31^{-}: \mathrm{H} 4$. The colicin V-resistant mutant was prepared by the method o Smith \& Huggins (1976). All other chromosomal mutants were obtained by treatment with $N$-methyl- $N^{\prime}-$ nitro- $N$-nitrosoguanidine (Glover, 1968).

Comparison of the ability of different derivatives of strain $\mathrm{H} 209$ to survive in the alimentary tract. Unless stated otherwise, each of the different plasmid-carrying and chromosomal mutant strains of $\mathrm{H} 209$ was compared with the $\mathrm{Nal}^{\mathrm{r}}$ parent strain from which they were all derived, except for $\mathrm{Fla}^{-}$and $\mathrm{Ent}^{+}$derivatives which were compared with a spectinomycin-resistant mutant of the Nal ${ }^{r}$ parent strain. Broth cultures of the 
derivative to be studied and of $\mathrm{H} 209$ were incubated in a shaking water bath at $37{ }^{\circ} \mathrm{C}$ for $24 \mathrm{~h}$. The two cultures were then centrifuged at $2500 \mathrm{~g}$ for $30 \mathrm{~min}$ and the deposits were resuspended in broth to the original volume. They were mixed together in the proportion of $1 \mathrm{ml}$ to $9 \mathrm{ml}$, one loopful was inoculated on to two plates of MacConkey agar and the remainder (approximately $10^{10}$ viable organisms) was quickly consumed by one of the human beings; this proportion was chosen because it had been successfully employed in our earlier investigation (Smith \& Huggins, 1976). At daily intervals thereafter, approximately $1 \mathrm{~g}$ of the faeces of the human beings was shaken with $10 \mathrm{ml}$ distilled water in a Griffin bottle shaker, SGL 200 (stroke $37.5 \mathrm{~mm}$, speed $275 \mathrm{~min}^{-1}$ ) for $10 \mathrm{~min}$; then $0.3 \mathrm{ml}$ samples were inoculated on to plates of MacConkey agar containing $20 \mu \mathrm{g}$ sodium nalidixate $\mathrm{ml}^{-1}$. Fifty of the $E$. coli colonies that grew on the plates were examined to see whether they consisted of organisms of the plasmid-carrying or mutant derivative of $\mathrm{H} 209$ or of $\mathrm{H} 209$ itself; 50 colonies from the inoculum were similarly examined. In the earlier stages of each experiment only two plates of medium were inoculated with each faceal specimen but in the final stages as many as six plates were inoculated to obtain the necessary 50 colonies. The ColV and the ColVI-K94 plasmids were both F-like, the former being repressed and the latter de-repressed; strains carrying the latter plasmid synthesized colicin Ia in addition to colicin V. Because strain $\mathbf{H} 209$ is moderately sensitive to colicin V, the strains carrying these two plasmids were compared with a mixture of $\mathrm{H} 209$ and a colicin V-resistant derivative of it, instead of only with the sensitive strain; there was no difference in the results.

\section{RESULTS AND DISCUSSION}

Of the 14 plasmid-carrying strains, only the ColV+ strain survived better in the alimentary tract of the two human beings than did the parent strain (Tables 1 and 2). Except in the experiment in human being no. 1 in which it formed the larger proportion of the inoculum, the ColVI-K94+ strain survived less well than the parent strain; this was especially noticeable in human being no. 2 and it was confirmed in repeat experiments. In human being no. 1 it was also compared directly with the $\mathrm{ColV}^{+}$strain. Of the 50 isolates examined from the inoculum, 44 were ColVI-K $94^{+}$. The corresponding figures for the 50 isolates obtained from the faeces on days 1 to 9 were $28,13,7,7,3,1,0,0$ and 0 , respectively. In both of two additional tests carried out in human being no. 2, a ColVI-K94+ derivative of an O78:K80 strain, B188, also survived less well than B 188 itself; a ColV ${ }^{+}$derivative of в 188 had previously been shown to survive much better in the alimentary tract of both human beings than B188 itself (Smith \& Huggins, 1976). Strain H209 carrying the repressed F plasmid survived as well as the parent strain, but the forms carrying the de-repressed $F$ and I plasmids survived less well, suggesting that the de-repressed state hinders survival. This may also account for the strain containing the ColVI-K94 plasmid surviving less well than the strain containing the ColV plasmid, because the former plasmid is de-repressed whereas the latter is repressed. Other genetic differences between the two plasmids could also be responsible; there is no definite evidence, for that matter, implicating colicin $\mathrm{V}$ itself in survival in the alimentary tract (Smith \& Huggins, 1976).

The $\mathrm{K}^{8} 8^{+}$strain survived less well than the parent strain and the remaining plasmidcarrying strains probably survived equally well. These included the $\mathrm{R}^{+}$and $\mathrm{R} 100^{+}$strains which had been included in the present study because they increased the resistance of $E$. coli K12 to the bactericidal activity of serum (Reynard \& Beck, 1976); Anderson (1974) had found that $\mathbf{R}^{+}$strains usually survived less well in the human alimentary tract than their $\mathrm{R}$ - counterparts. In human being no. 1, the survival of an $E$. coli $\mathrm{K} 12$ strain of about $3 \mathrm{~d}$ was not increased by the presence of an LT Ent plasmid (Smith \& Linggood, 1971 $a$ ) or an ST Ent plasmid (Smith \& Linggood, 1972) in that strain.

Of the chromosomal mutants, the $\mathrm{O9}^{-}: \mathrm{K} 31^{-}$, thy and his strains survived less well in both human beings than the parent strain and the $\mathrm{K}$ - and lac strains probably survived equally well. Similar results were obtained when the $\mathrm{Fla}^{+} / \mathrm{Fla}^{-}$experiment in human being no. 1 was repeated; the evenness of the distribution of the Fla ${ }^{+}$and $\mathrm{Fla}^{-}$organisms in stool specimens was established by examining five discrete portions of each stool on each occasion. The median (with the range in parentheses) of the number of 50 isolates that were $\mathrm{Fla}^{+}$in the five portions of the stool examined on each of these $7 \mathrm{~d}$ was 30 (26 to 36), 28 (26 to 38), 


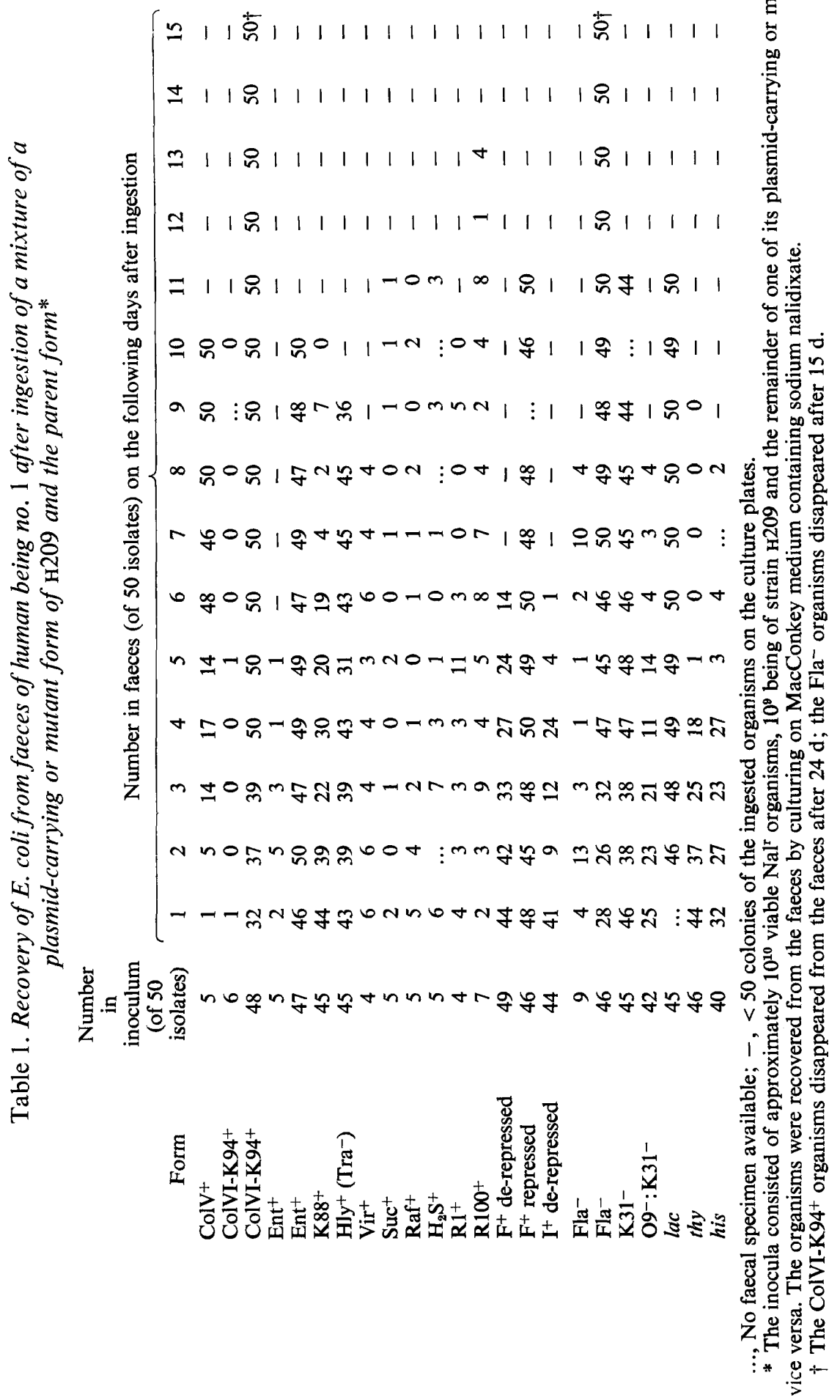




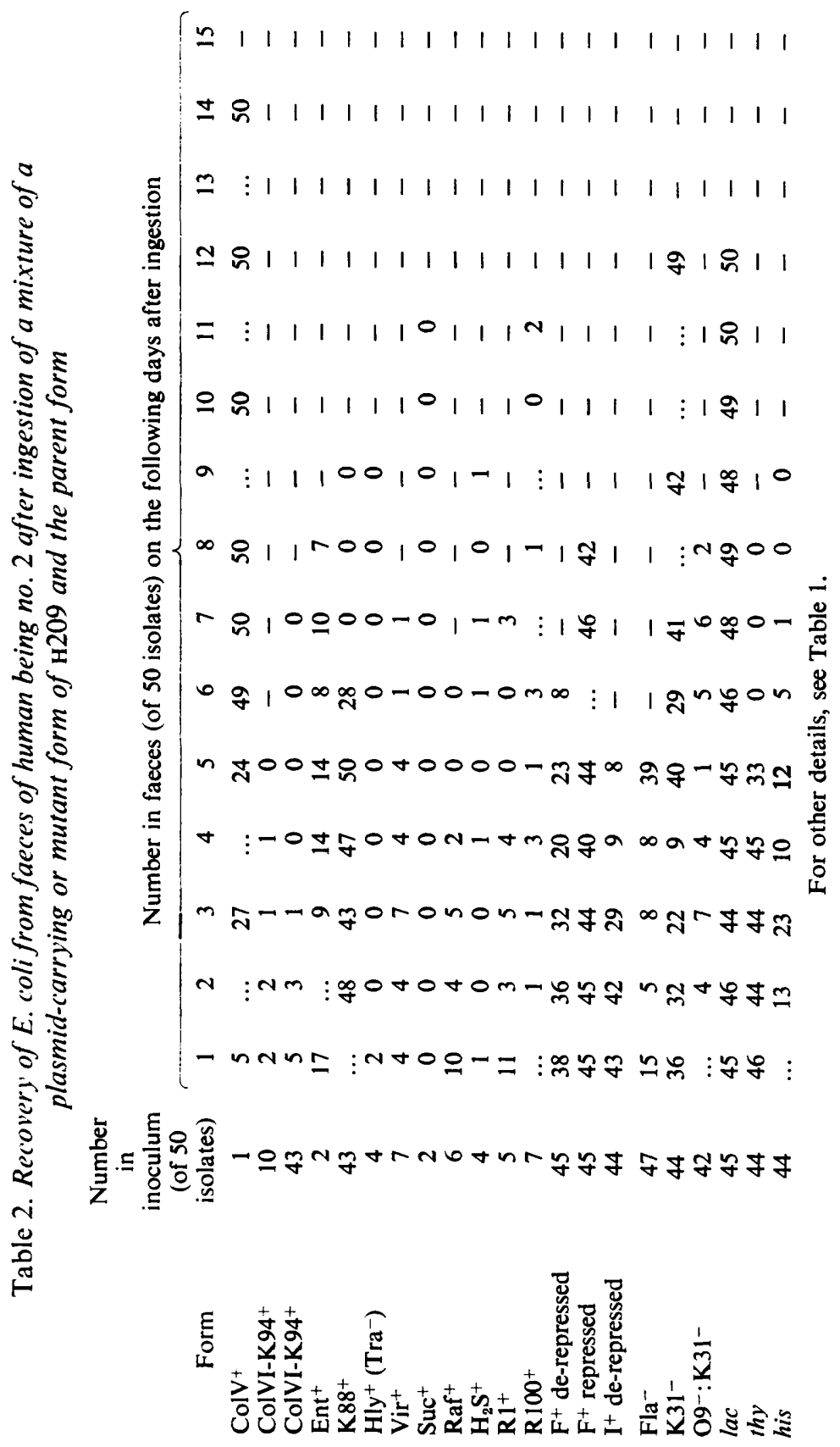


34 ( 27 to 36 ), 36 ( 31 to 39 ), 37 ( 33 to 40 ), 38 ( 35 to 40 ) and 38 ( 31 to 41 ). One test was carried out in each human being in which the usual Nal ${ }^{\mathrm{r}}$ parent strain was used in place of the $\mathrm{Nal}^{\mathrm{r}} \mathrm{Spc}^{\mathrm{r}}$ strain, all isolates being individually tested for motility. Again, there was no evidence of $\mathrm{Fla}^{+}$organisms becoming more common in the faeces than $\mathrm{Fla}^{-}$ones. Of the 50 isolates from the inoculum given human being no. 1, 47 were Fla-. The corresponding figures for the isolates from faeces on days 1,10 and 12, were 41,45 and 50 , respectively. Those for human being no. 2 were, for the inoculum, 47 and, for the faeces on days 1,6 and 7, 48, 49 and 50, respectively. In fact the Fla- state may have enhanced survival.

The conclusions that can be drawn from our experiments are, of course, limited because they were mainly performed on only two human beings and with only one strain of E. coli. The fact that this strain persisted for only a short period in the alimentary tract implies that any small differences in colonizing ability which could be important in the long term would have gone undetected. Despite the shortness of this period, it sometimes varied considerably from experiment to experiment indicating that to obtain meaningful comparisons, strains should be tested at the same time, as they were in the present study; comparisons made at different times could yield erroneous results.

We are grateful to Mrs Frances Richards for her capable technical help. We also wish to thank Dr P. M. Biggs, Dr B. Rowe and Miss Susan Shaw for assistance in a variety of ways.

\section{REFERENCES}

Anderson, J. D. (1974). The effect of $R$ factor carriage on the survival of Escherichia coli in the human intestine. Journal of Medical Microbiology 7, 85-90.

FREDERICQ, P. (1963). On the nature of colicinogenic factors: a review. Journal of Theoretical Biology 4, 159-165.

Glover, S. W. (1968). In Experiments in Microbial Genetics, p. 17. Edited by R. C. Clowes \& W. Hayes. Oxford and Edinburgh: Blackwell Scientific Publications.

ØRSkov, I. \& ØRskov, F. (1973). Plasmid-determined $\mathrm{H}_{2} \mathrm{~S}$ character in Escherichia coli and its relation to plasmid-carried raffinose fermentation and tetracycline resistance characters. Journal of General Microbiology 77, 487-489.

Reynard, A. M. \& BeCK, M. E. (1976). Plasmidmediated resistance to the bactericidal effects of normal rabbit serum. Infection and Immunity 14, 848-850.

Smith, H. Williams (1970). The transfer of antibiotic resistance between strains of enterobacteria in chickens, calves and pigs. Journal of Medical Microbiology 3, 165-180.

Smith, H. Williams (1974). A search for transmissible pathogenic characters in invasive strains of Escherichia coli: the discovery of a plasmidcontrolled toxin and a plasmid-controlled lethal character closely associated, or identical, with colicine V. Journal of General Microbiology 83, 95-111.

Smith, H. Williams \& Huggins, M. B. (1976).
Further observations on the association of the colicine $\mathrm{V}$ plasmid of Escherichia coli with pathogenicity and with survival in the alimentary tract. Journal of General Microbiology 92, 335350.

Smith, H. Williams \& Linggood, M.A. (1971a). The transmissible nature of enterotoxin production in a human enteropathogenic strain of Escherichia coli. Journal of Medical Microbiology 4, 301-305.

Smith, H. Williams \& Linggood, M. A. (1971b). Observations on the pathogenic properties of the K88, Hly and Ent plasmids of Escherichia coli with particular reference to porcine diarrhoea. Journal of Medical Microbiology 4, 467-485.

Smith, H. Williams \& LingGOOD, M. A. (1972). Further observations on Escherichia coli enterotoxins with particular regard to those produced by atypical piglet strains and by calf and lamb strains: the transmissible nature of these enterotoxins and of a $\mathrm{K}$ antigen possessed by calf and lamb strains. Journal of Medical Microbiology 5, 243-250.

Smith, H. Williams \& Parsell, Z. (1975). Transmissible substrate-utilizing ability in enterobacteria. Journal of General Microbiology 87, 129-140.

Tomoeda, M., InUzuKa, M., Kubo, N. \& NaKama, S. (1968). Effective elimination of drug resistance and sex factors in Escherichia coli by sodium dodecylsulphate. Journal of Bacteriology 95, 1078-1089. 